\title{
Bone engineering by cell sheet technology to repair mandibular defects
}

\author{
XIULI SHAN and DESHAN HU \\ Department of Stomatology, The Fifth People's Hospital of Jinan, \\ Jinan, Shandong 250022, P.R. China
}

Received May 18, 2017; Accepted September 5, 2017

DOI: $10.3892 / \mathrm{etm} .2017 .5118$

\begin{abstract}
Effectiveness of bone engineering by cell sheet technology to repair canine mandibular injuries was investigated. Cell sheets were produced from canine stem cells cultured by density gradient centrifugation and osteoblast induction. A scaffold surface of polylactic-co-glycolic acid (PLGA) copolymer was wrapped with cell sheets. Mandibular injuries were created in 12 healthy dogs followed by implantation of PLGA with (experimental group; $\mathrm{n}, 6$ ) and without (control group; $\mathrm{n}, 6$ ) cell sheets. The progression of the implants was examined at 3,9 , and 12 weeks postoperative. At postoperative 12 weeks, the graft mostly replaced the new bone in the experimental group, compact similar to normal bone was formed at lingual position and the broken end of the bone was normally healed. The bone mass in the control group was 2.5 , which was significantly lower than the 4.5 in the experimental group. The optical density of the new bone in the experimental group was significantly higher than that in the control group. The experimental group had more haversian canal and red bone marrow and contained a larger number of lamellar bone than the control group. Overall, satisfactory bone engineering containing lamellar bone can be established by cell sheet technology, which is an ideal method to repair mandibular injuries.
\end{abstract}

\section{Introduction}

Mandibular tissue defects are mainly caused by developmental deformity, trauma, and tumor resection $(1,2)$. Trypsin digestion and cell inoculation are the traditional methods to repair mandibular tissue defects. This method is prone to reduce cell activity, which leads to mass cell death, lower utilization rate of cells, difficulty in formation of dense bone tissue and

Correspondence to: Dr Xiuli Shan, Department of Stomatology, The Fifth People's Hospital of Jinan, 24297 Jingshi Road, Jinan, Shandong 250022, P.R. China

E-mail: drxiulishan@163.com

Key words: cell sheet technology, tissue engineering bone, mandibular defect other deficiencies. These complications hinder the recovery expected following the clinical treatment (3-5). To improve the utilization rate of the transplanted cells, the harvest and inoculation of bioactive seed cells need to be optimized using bone tissue engineering (6). The development of bone tissue engineering provides a new avenue for the repair of jaw injuries. Cellular secretions and maintenance of tissue structures can be effectively retained by cell sheet technology, which reduces the loss of seed cells $(7,8)$. In this study, we applied cell sheet technology to bone tissue engineering. The scaffold surface of polylactic-co-glycolic acid (PLGA) is covered with a cell sheet and is implanted in the region of mandibular injury in dogs to establish normal functional bone and bone structure.

\section{Materials and methods}

Experimental animals. We obtained 12 healthy mongrel dogs from the Laboratory Animal Center of The Fifth People's Hospital of Jinan, regardless of their sex, weighing 21-32 kg and ages 14-23 months.

Main instruments and reagents. Temperature-responsive culture dish (Shanghai Qifu Biotechnology Co., Ltd., Shanghai, China), Dulbecco's modified Eagle's medium nutrient solution (Shanghai Genmed Gene Pharmaceutical Technology Co., Ltd., Shanghai, China), PLGA scaffold (Changzhou New District Jiasen Medical Bracket Instrument), inverted phase contrast microscope (Shanghai Pooher Optoelectronics Technology Co., Ltd., Shanghai, China), scanning electron microscope (Star Joy Co., Ltd., Guangzhou, China), cell incubator (Precision Instrument, Shanghai, China), trypsin (Peptone Biological Products, Shandong, China) and osteogenic inducing fluid (Han Heng Biotechnology, Shanghai, China).

Stem cell isolation and culture. A total of $15 \mathrm{ml}$ of bone marrow blood was extracted from experimental dogs under anesthesia. Stem cells were isolated by density gradient centrifugation and the density of stem cells was diluted to $10^{7}$ cells $/ \mathrm{ml}$ in nutrient solution. The cells were inoculated in $45 \mathrm{ml}$ culture flasks and cultured under saturated humidity $\left(36^{\circ} \mathrm{C}, 6 \% \mathrm{CO}_{2}\right)$, followed by observation under the inverted phase contrast microscope. When cells reached $70 \%$ of confluence, they were digested with 
trypsin containing $0.03 \%$ elhylene diamine tetraacetic acid and subcultured at a 1:2 ratio.

Osteogenic induction of stem cells. To the subcultured cells we added $5 \mathrm{ml}$ high-glucose medium containing $11 \%$ fetal calf serum and osteogenic inducing media and cultured under saturated humidity $\left(36^{\circ} \mathrm{C}, 6 \% \mathrm{CO}_{2}\right)$ to promote the induction of stem cells into osteoblasts.

Stem cell sheet preparation. The stem cells after osteogenic induction were digested with trypsin, inoculated at a density of $10^{7}$ cells $/ \mathrm{ml}$ in temperature-responsive culture dish after, and then placed under saturated humidity $\left(36^{\circ} \mathrm{C}, 6 \% \mathrm{CO}_{2}\right)$. The stem cells were laid at the bottom of culture dish 12 days later. Subsequently, the culture dish was placed in the calorstat for $25 \mathrm{~min}$ and stem cells and the bottom of culture dish were separated to form the cell sheet (3).

Stem cell inoculation and scaffold surface wrapped with cell sheet. Scaffolds were soaked and divided in two groups. In group A, the scaffold surface was wrapped with cell sheets (experimental group). The scaffold surface in group B was not wrapped with cell sheets (control group). The cells were cultured under saturated humidity $\left(36^{\circ} \mathrm{C}, 6 \% \mathrm{CO}_{2}\right)$ for 5 days, followed by scanning and observing under the electron microscope. The study was approved by the Ethics Committee of the Fifth People's Hospital of Jinan.

Canine mandibular defect implantation. A total of 12 dogs were divided into experimental and control groups, with 6 animals in each group. After intravenous anesthesia, a $6 \mathrm{~cm}$-long incision was made in the lower edge of the mandible on both sides and the skin, muscle and fascia were cut open to expose the mandible body. A trapezoid (up broad and down narrow) injury with shape similar to the PLGA scaffold was created in both mandibles. We retained the inferior alveolar nerves and vessels to prevent rejection of the implant. Scaffolds covered and not covered with cell sheets were implanted in the experimental and control groups, respectively. The groove of the scaffold was embedded in the mandibular nerve vessel, and soft tissue was carefully sutured, followed by fixation of the scaffold; $3 \times 10^{6} \mathrm{U}$ of penicillin were administered every day for one week following surgery.

Observation indexes. i) Gross observation: two experimental animals were sacrificed at postoperative 3,9 and 12 weeks, and bilateral mandibles were removed for gross observation.

ii) Imaging: X-ray imaging of mandibles were obtained under the same projection conditions. Optical density was analyzed and measured by Image-Pro Plus 6.0 (Media Cybernetics Inc., Rockville, MD, USA) software.

iii) Histological examination: Partial specimen tissues of the same region were removed and processed by conventional demineralization, fixation, staining, sliced, and followed by observation under inverted phase contrast microscope.

iv) The ratio of bone tissue surface on each slice was calculated by Adobe Photoshop 7.0 (Adobe Systems, Inc., San Jose, CA, USA) and Image-Pro Plus 6.0 (Media Cybernetics Inc., Rockville, MD, USA) software. To obtain accurate results, the

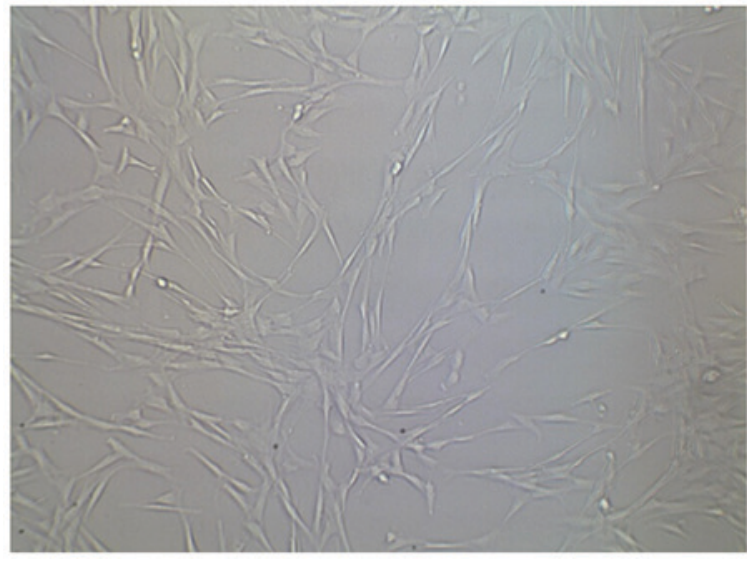

Figure 1. Scanning electron microscope observation of cell sheets. Cells are widely distributed and tightly adhered. A large amount of extracellular matrix components can be seen.

percentage of bone area was calculated after extracting the serial slices of the same part from all the specimens.

Statistical analysis. SPSS 20.0 (IBM Corp., Armonk, NY, USA) statistical software was used for analysis. The differences of optical density, bone mass and bone area between two groups were compared by analysis of variance (ANOVA). A P<0.05 was considered to indicate a statistically significant difference.

\section{Results}

Examination of cultured stem cells prior to implantation. Following culture of cells with and without scaffold, we proceeded to examine them by scanning electron microscopy. Cell sheets in the experimental group were widely distributed on the surface on the small openings of the scaffold material 7 days after cell inoculation (Fig. 1). Cells were tightly adhered and fully extended, they were connected with each other and a large amount of extracellular matrix components could be observed.

Gross observation of mandibular implants. All the animals survived the surgery and implantation. The gross observation of the 12 dogs showed that the scaffold material was wrapped with soft tissue at postoperative 3 weeks, but the scaffold structure could still be seen. The broken end of bone around the scaffold was distinct and it was relatively soft to the touch. We found no differences between the experimental and control groups. At postoperative 9 weeks, partial scaffold structures could be seen on both sides. The combination of broken end with scaffold was relatively compact, with unclear boundaries, showing less absorption of the lower part of scaffold. The scaffold was significantly less absorbed in the experimental group compared to the control group. At postoperative 12 weeks, the lateral bone injury was replaced by new bone tissue repair in the experimental group. The compact bone at lingual position was similar to normal bone and the broken end of the bone was healed, showing the similar hardness to the surrounding bone tissues (Fig. 2A). The bone mass in the control group was 2.5 , which was significantly lower 
A

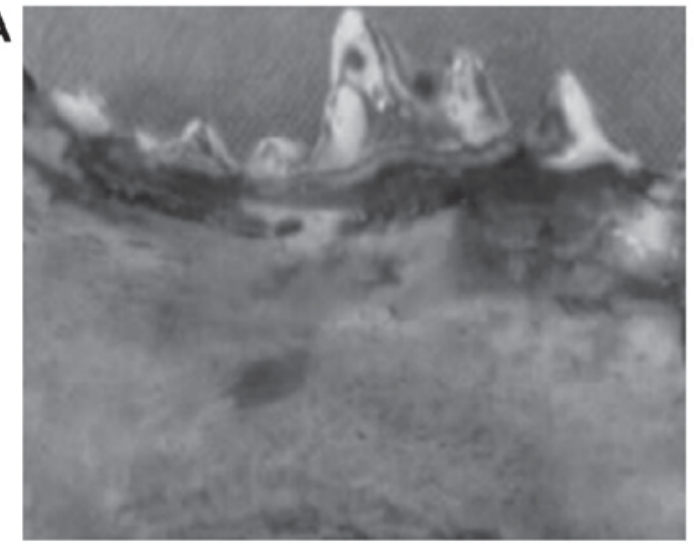

B

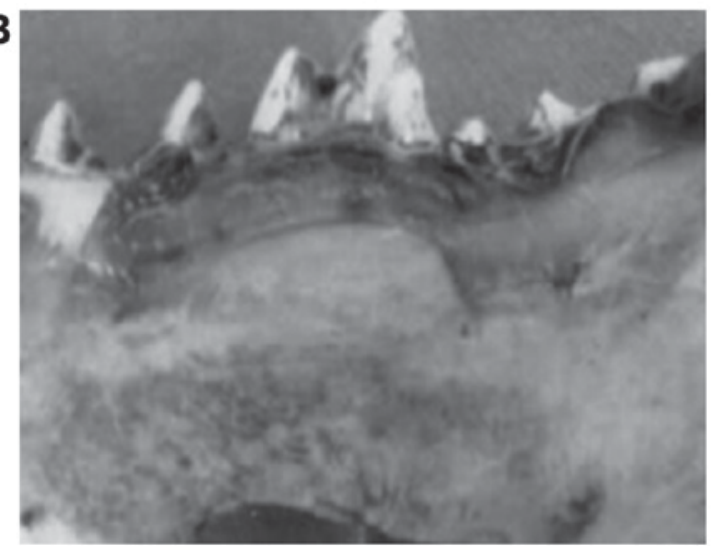

Figure 2. Gross observation of grafts at postoperative 12 weeks. (A) Location of the lateral bone injury in the experimental group is replaced by new bone tissue repair, the compact bone at lingual position is similar to normal bone and the broken end of bone is normally healed, showing similar hardness to the surrounding bone tissues; (B) obvious bone injury can still be seen at mandibular position in the control group.
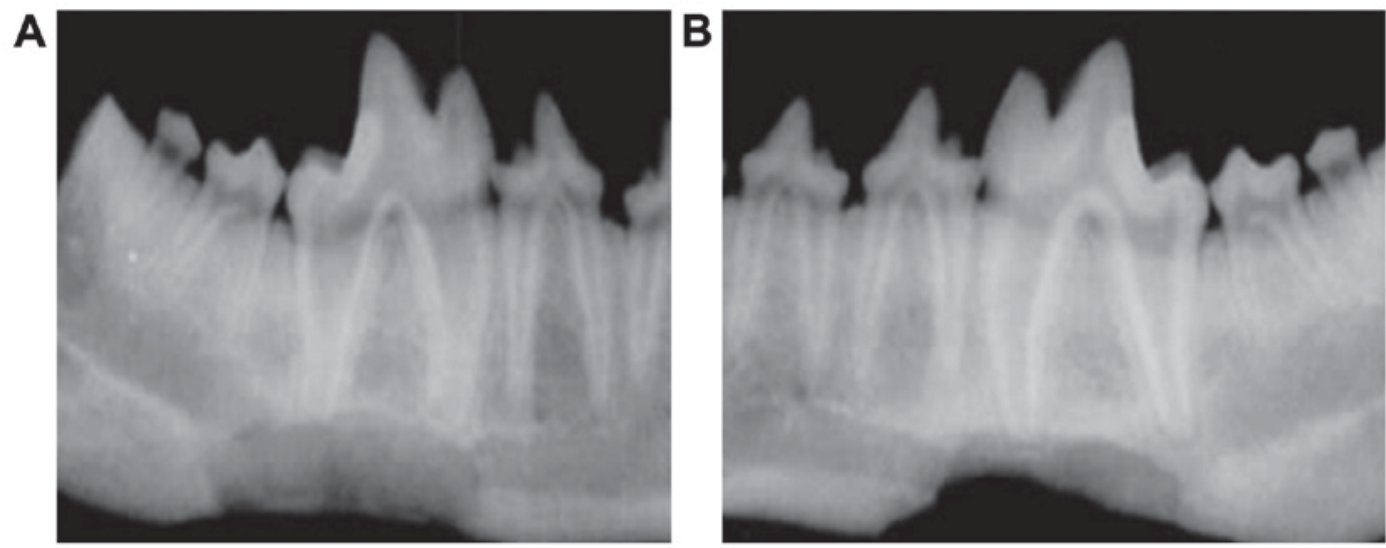

Figure 3. X-ray imaging at postoperative 12 weeks. (A) Experimental group; (B) control group. The irregular bone trabecular shadow can still be seen within 3-12 weeks after material being implanted, and with the extending of time, the amount of bone trabecular is increased, and high-density fracture line can be seen at the broken end of the bone.

Table I. Postoperative optical absorbance over time.

\begin{tabular}{lccc}
\hline & \multicolumn{3}{c}{ Postoperative weeks } \\
\cline { 2 - 4 } Groups & 3 & 9 & 12 \\
\hline Control & $0.545 \pm 0.017$ & $0.683 \pm 0.043$ & $0.711 \pm 0.012$ \\
Experimental & $0.621 \pm 0.023$ & $0.802 \pm 0.065$ & $0.945 \pm 0.033$ \\
t-test & 7.031 & 8.004 & 9.562 \\
P-value & $<0.05$ & $<0.05$ & $<0.05$ \\
\hline
\end{tabular}

than 4.5 in the experimental group $(\mathrm{P}<0.05)$. In contrast, the mandibular bone injury could still be seen in the control group (Fig. 2B).

Bone imaging. Next, we conducted X-ray imaging of the injured mandibles to examine the recovery in more detail. The optical density of mandibles in the experimental and control groups increased gradually over time from postoperative 3-12 weeks and the differences were statistically significant at different time points $(\mathrm{P}<0.05)$. The optical density was significantly higher in the experimental than that in control group at the same postoperative time point (Table I and Fig. 3). At postoperative 12 weeks, the optical density for the experimental group reached the highest value, but the optical density was still lower than that of normal bone tissue. The irregular bone trabecular shadow could still be seen within 3-12 weeks after material implantation. Over time, the amount of bone trabecular increased and a high-density fracture line could be observed at the broken end of the bone (Fig. 3).

Histological observation of osteoblast. At postoperative 12 weeks, the bone trabecula was thick and large at bilateral positions in the experimental group (Fig. 4A). The haversian canal was abundant and concentric lamellar bone could be seen around it, with red bone marrow and a large number of bone cells in good condition. The vessels in the bone marrow were abundant containing much calcium salt deposition. The bone trabecula and the haversian canal were smaller in control group (Fig. 4B).

Tissue morphology. Finally, we examined the bone area recovered after implantation. Bone areas in the experimental group were significantly larger than those in the control group at postoperative 9 and 12 weeks $(\mathrm{P}<0.05)$ (Fig. 5). 

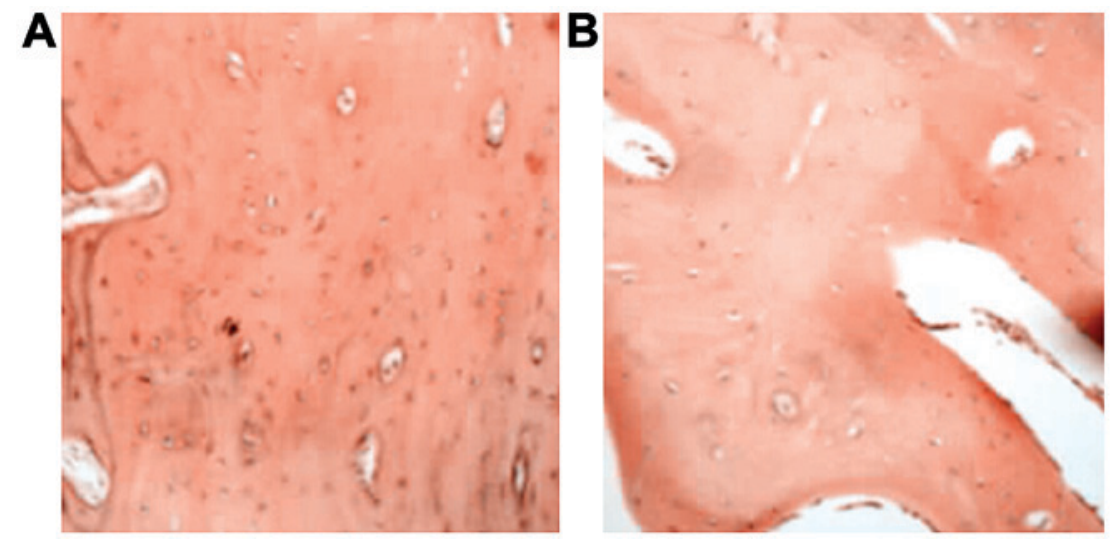

Figure 4. Histological observation at postoperative 12 weeks. (A) Experimental group; (B) control group. The bone trabecula is thick and large at bilateral positions in experimental group; the haversian canal is abundant and concentric lamellar bone can be seen around it. The bone trabecula is smaller in control group and the haversian canal is reduced.

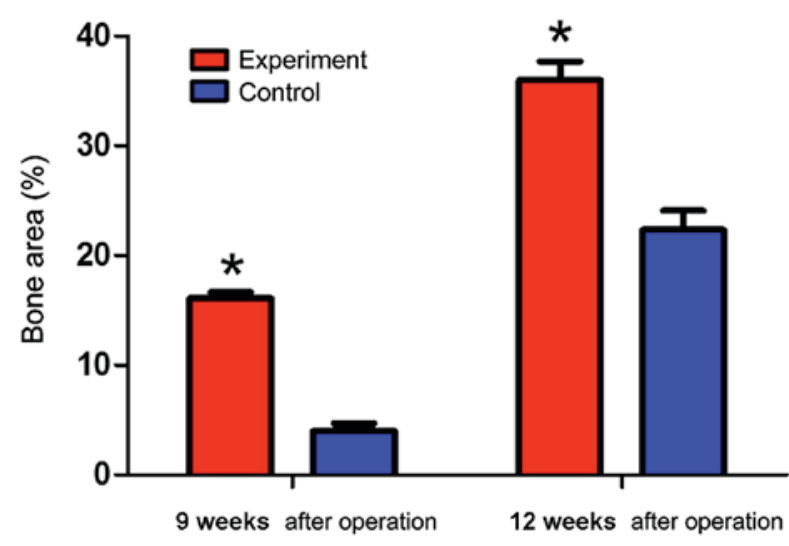

Figure 5. Percentage of bone area on histological section by image analysis software. Bone areas in the experimental group are significantly larger than those in the control group $\left({ }^{*} \mathrm{P}<0.05\right)$.

\section{Discussion}

The repair of jaw injury is still a difficult clinical problem that needs an urgent solution (9). In previous years, the development of bone tissue engineering provides new approaches to repair jaw injuries. Good scaffold materials and seed cells are critical to promote the development of bone tissue (10-12). Cell sheets, a method of harvesting seed cells, obtains seed cells via temperature induction $(13,14)$. Cells are laid at the bottom of a temperature-responsive culture dish and cultured for 12 days at $25^{\circ} \mathrm{C}$, until the formation of a hydrated film between the cells and the material at the bottom of the dish (15). Cells are completely separated from the culture dish, thereby forming cell sheets. Cell sheets have multiple advantages and have been applied in many research fields (16-18). For instance, tubular myocardial structure established by cell sheet technology demonstrate a degree of functionality (19). Corneal tissue can also be rebuilt on the oral mucosa via cell sheet technology (20). New bone tissue with similar structure to the normal bone can be established and grafted.

Here, we established tissue engineering bone cells by cell sheet technology and plastic scaffold. Canine stem cells were induced into osteoblasts to form cell sheets and scaffold material covered with the cell sheets were implanted in canine mandibular injuries. The porous scaffold material, which provides an adhesion surface for the stem cells, contributes to the smooth growth of cells in the injury site, showing a higher degree of plasticity and strength (21). The PLGA scaffold used in this experiment demonstrates better biocompatibility with biological cells. The PLGA scaffold is a three-dimensional net-like structure and its gap size is conducive to bone cell and vessel growth, thus ensuring the consistency of growth rate of new bone with scaffold degradation rate (22-24). The PLGA scaffold used in this experiment adopts a trapezoidal shape. A groove is maintained on the dorsal side of the scaffold to accommodate the mandibular nerve vessels, allowing the inferior alveolar artery to penetrate into the inner part of scaffold, thereby creating conditions to provide blood supply for the growing bone tissue.

In conclusion, the satisfactory tissue engineering of bone containing lamellar bone can be established by cell sheet technology, making this technology an ideal method to repair mandibular injuries. However, there are still multiple problems in establishing engineered bone tissue, which require further research. The most critical problems are the difficulty of producing cell sheets and achieving highly functional scaffolds wrapped with cell sheets.

\section{References}

1. Li H, Sun S, Liu H, Chen H, Rong X, Lou J, Yang Y, Yang Y and Liu H: Use of a biological reactor and platelet-rich plasma for the construction of tissue-engineered bone to repair articular cartilage defects. Exp Ther Med 12: 711-719, 2016.

2. McDaniel JS, Pilia M, Raut V, Ledford J, Shiels SM, Wenke JC Barnes B and Rathbone CR: Alternatives to autograft evaluated in a rabbit segmental bone defect. Int Orthop 40: 197-203, 2016.

3. Wang L, Zou D, Zhang S, Zhao J, Pan K and Huang Y: Repair of bone defects around dental implants with bone morphogenetic protein/fibroblast growth factor-loaded porous calcium phosphate cement: A pilot study in a canine model. Clin Oral Implants Res 22: 173-181, 2011.

4. Kang BJ, Ryu HH, Park SS, Koyama Y, Kikuchi M, Woo HM, Kim WH and Kweon OK: Comparing the osteogenic potential of canine mesenchymal stem cells derived from adipose tissues, bone marrow, umbilical cord blood, and Wharton's jelly for treating bone defects. J Vet Sci 13: 299-310, 2012.

5. Heydarkhan-Hagvall S1, Schenke-Layland K, Yang JQ, Heydarkhan S, Xu Y, Zuk PA, MacLellan WR and Beygui RE: Human adipose stem cells: A potential cell source for cardiovascular tissue engineering. Cells Tissues Organs 187: 263-274, 2008 
6. Yao C, Bu L, Wang K, Li N, Wang L and Yu Y: A study of repairing mandibular defect using tissue engineering bone with bone marrow stem cells cell sheets in dog. Hua Xi Kou Qiang Yi Xue Za Zhi 30: 229-233, 2012 (In Chinese).

7. Udehiya RK, Amarpal, Aithal HP, Kinjavdekar P, Pawde AM, Singh R and Taru Sharma G: Comparison of autogenic and allogenic bone marrow derived mesenchymal stem cells for repair of segmental bone defects in rabbits. Res Vet Sci 94: 743-752, 2013.

8. Li H,Dai K, Tang T,Zhang X, Yan M and Lou J: Bone regeneration by implantation of adipose-derived stromal cells expressing BMP-2. Biochem Biophys Res Commun 356: 836-842, 2007.

9. Sumide T, Nishida K, Yamato M, Ide T, Hayashida Y, Watanabe K, Yang J, Kohno C, Kikuchi A, Maeda N, et al: Functional human corneal endothelial cell sheets harvested from temperature-responsive culture surfaces. FASEB J 20 : 392-394, 2006.

10. Tsai RJ and Tsai RY: From stem cell niche environments to engineering of corneal epithelium tissue. Jpn J Ophthalmol 58: 111-119, 2014.

11. Yuan J, Zhang WJ, Liu G, Wei M, Qi ZL, Liu W, Cui L and Cao YL: Repair of canine mandibular bone defects with bone marrow stromal cells and coral. Tissue Eng Part A 16: 1385-1394, 2010

12. Girolamo ND: Adult human corneal epithelial stem cells In: Adult Stem Cells. Turksen K (ed). Springer, New York, NY, pp163-197, 2014.

13. Kumashiro Y, Yamato M and Okano T: Cell attachment-detach ment control on temperature-responsive thin surfaces for novel tissue engineering. Ann Biomed Eng 38: 1977-1988, 2010.

14. Raffaghello L, Bianchi G, Bertolotto M, Montecucco F, Busca A, Dallegri F, Ottonello L and Pistoia V: Human mesenchymal stem cells inhibit neutrophil apoptosis: A model for neutrophil preservation in the bone marrow niche. Stem Cells 26: 151-162, 2008.

15. Kaneshiro N, Sato M, Ishihara M, Mitani G, Sakai H and Mochida J: Bioengineered chondrocyte sheets may be potentially useful for the treatment of partial thickness defects of articular cartilage. Biochem Biophys Res Commun 349: 723-731, 2006.
16. Gao Z, Chen F, Zhang J, He L, Cheng X, Ma Q and Mao T: Vitalisation of tubular coral scaffolds with cell sheets for regeneration of long bones: A preliminary study in nude mice. Br J Oral Maxillofac Surg 47: 116-122, 2009.

17. Ueyama Y, Yagyuu T, Maeda M, Imada M, Akahane M, Kawate K, Tanaka Y and Kirita T: Maxillofacial bone regeneration with osteogenic matrix cell sheets: An experimental study in rats. Arch Oral Biol 72: 138-145, 2016.

18. Cui L, Liu B, Liu G, Zhang W, Cen L, Sun J, Yin S, Liu W and Cao Y: Repair of cranial bone defects with adipose derived stem cells and coral scaffold in a canine model. Biomaterials 28: 5477-5486, 2007.

19. Vilquin JT and Rosset P: Mesenchymal stem cells in bone and cartilage repair: Current status. Regen Med 1: 589-604, 2006.

20. Binnebösel M, Ricken C, Klink CD, Junge K, Jansen M and Schumpelick V: Safe rebuilding of the periodontal loss an experimental study. Bull Pol Acad Sci Tech Sci 63: 527-532, 2016.

21. Li Y, Zhao S, Nan X, Wei H, Shi J, Li A and Gou J: Repair of human periodontal bone defects by autologous grafting stem cells derived from inflammatory dental pulp tissues. Stem Cell Res Ther 7: 141-148, 2016.

22. Jose MV, Thomas V, Johnson KT, Dean DR and Nyairo E: Aligned PLGA/HA nanofibrous nanocomposite scaffolds for bone tissue engineering. Acta Biomater 5: 305-315, 2009.

23. Yan $\mathrm{H}$ and Tsujii $\mathrm{K}$ : Thermo-responsive poly(N-isopropylacrylamide) gel containing polymeric surfactant poly [2-(methacryloyloxyl)decylphosphate]: Correlation between rapid collapsing characters and micelles of polymeric surfactant. J Oleo Sci 57: 401-405, 2008.

24. Chen T, Wang Y, Bu L and Li N: Construction of functional tissue-engineered bone using cell sheet technology in a canine model. Exp Ther Med 7: 958-962, 2014. 